\title{
Comparative pronounceability ratings ( $p$ ) of 100 CVCs in two college populations
}

A sample of $100 \mathrm{CVCs}$ was presented to $200 \mathrm{Ss}$ from widely-separated college populations at the Universities of Georgia and Montana in order to obtain comparative ratings of pronounceability (p). The results indicated high withinpopulation reliability coefficients $(r \geq 98)$ and a high betwe en-population correlation coefficient $(r=.975)$. When the ratings were grouped by fives into 20 pairs of means, the Montana norms regressed linearly on the Georgia norms with $r=.993$.

Among various quantitative characteristics of verbal material that have been found to be significant factors in verbal learning and behavior is the relative ease or difficulty of pronouncing consonant-vowel-consonant (CVC) trigrams. Originated by Underwood \& Schulz (1960), and given the symbol p by Noble (1963), pronounceability is defined by mean ordinal judgments on a 9-point scale as follows:

$$
p=\frac{1\left(f_{e}\right)+\ldots+5\left(f_{a}\right)+\ldots+9\left(f_{h}\right)}{N}
$$

where $N=$ total number of Ss rating a given $\mathrm{CVC}, \mathrm{f}_{e}=$ frequency of ratings in the "Easy" category, $f_{a}=$ frequency of ratings in the "Average" category, and $f_{h}=$ frequency of ratings in the "Hard" category. Because of the importance Underwood and Schulz have assigned to $\mathrm{p}$ in the analysis of verbal learning phenomena as a potentially more fundamental variable than either meaningfulness (m) or scaled meaningfulness (m), it is necessary to evaluate its reliability within and between populations before testing for differential validity.

\section{Method}

To this end a sample of $100 \mathrm{CVCs}$ representing the full range of 2100 items was drawn from the Montana $\underline{m^{\prime}}$ scale (Noble, 1961). Following the exact procedures stipulated by Underwood \& Schulz (1960, pp. 23-24), these $100 \mathrm{CVCs}$ were placed in random order and presented in two columns of 25 on each of two pages of a mimeographed test booklet. Half the Ss received the pages in one order, the other half the reverse order. Instructions were reproduced verbatim, and the 9-point rating scale was reproduced at the top of each page. Two hundred Ss divided equally between the undergraduate populations at the Universities of Montana and Georgia were selected. They were tested at the northwestern and southeastern institutions in 1964 and 1965 , respectively.

Results

After weighting Ss' scores according to Eq. 1, intergroup correlation coefficients were computed on the basis of a random split of Ss responding to the $100 \mathrm{CVCs}$ in each college sample. In other words, a separate Pearson $r$ was calculated for 100 pairs of mean $\mathrm{p}$ values each determined from $50 \mathrm{Ss}$ ' ratings. The results, corrected for attenuation in each college group, indicated high within-population rellability coefficients: $r \geq .98$. A similar analysis of betweenpopulation stability was made by computing the correlation between the 100 pairs of mean $p$ values each determined from 100 Ss' ratings: $r=.975$. Finally, as shown in Fig. 1, the ratings were grouped by fives into 20 pairs of means to evaluate the regression of the Montana norms $\left(p_{m}\right)$ on the Georgia norms $\left(p_{g}\right)$. In this procedure, initial grouping was done by reference to the $\mathrm{p}_{\mathrm{g}}$ means; then ties were broken by reference to the $p_{m}$ means. The equation for the straight line in Fig. 1, determined by the method of least squares is:

$$
\mathrm{p}_{\mathrm{m}}=.882\left(\mathrm{p}_{\mathrm{g}}\right)+.459
$$

Its correlation coefficient, derived from the 20 paired scores plotted in Fig. 1 , has the value $r=.993$. Table 1 presents the mean pronounceability ratings (D) based on the combined Georgia and Montana norms.

Discussion

From the graphical and statistical analyses pro-

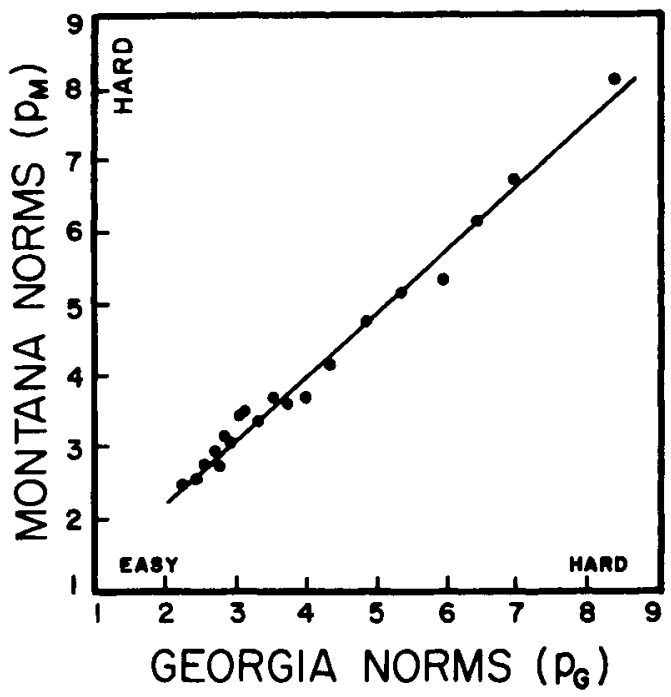

Fig. 1. Linear regression of Montana norms $\left(p_{m}\right)$ on Georgia norms $\left(p_{g}\right)$ for grouped data $(N=100$ Ss each). 
Table 1. Mean Pronounceability Ratings (p) of 100 Selected CVCs Based on Combined Georgia and Montana Norms as Rated by 200 Ss

\begin{tabular}{llllllllllll}
\multicolumn{2}{l}{ No. } & CVC & $\overline{\mathbf{p}}$ & \multicolumn{1}{l}{ No. } & CVC & $\overline{\mathbf{p}}$ & No. & CVC & $\overline{\mathbf{p}}$ & No. CVC & $\overline{\mathbf{p}}$ \\
\hline 1 & BAN & 2.54 & 26 & GAL & 3.46 & 51 & MER & 4.46 & 76 & SEX & 3.32 \\
2 & BAT & 2.28 & 27 & GEM & 3.27 & 52 & NAT & 3.31 & 77 & SIR & 3.29 \\
3 & BOY & 3.31 & 28 & GIS & 6.14 & 53 & NEB & 3.91 & 78 & SUM & 3.06 \\
4 & BUG & 2.80 & 29 & GOD & 3.17 & 54 & NEG & 4.69 & 79 & SUN & 2.19 \\
5 & BUS & 3.16 & 30 & GUM & 3.56 & 55 & NIV & 5.80 & 80 & TED & 2.67 \\
6 & CAD & 3.53 & 31 & HAY & 2.62 & 56 & NOB & 3.72 & 81 & TEX & 3.29 \\
7 & CAL & 3.34 & 32 & HED & 4.20 & 57 & NOV & 5.46 & 82 & TIX & 4.98 \\
8 & CAN & 2.36 & 33 & HEY & 3.44 & 58 & NOW & 3.16 & 83 & TOP & 2.87 \\
9 & CAR & 2.66 & 34 & HID & 3.64 & 59 & NUT & 2.72 & 84 & TOV & 6.26 \\
10 & CAW & 5.17 & 35 & HOT & 2.74 & 60 & PAG & 5.61 & 85 & WAR & 3.88 \\
11 & COD & 3.94 & 36 & HOV & 6.26 & 61 & PET & 2.75 & 86 & WAY & 2.58 \\
12 & CON & 2.80 & 37 & HOX & 5.38 & 62 & PID & 4.54 & 87 & WED & 3.45 \\
13 & CUP & 3.01 & 38 & HUB & 3.50 & 63 & PIG & 2.97 & 88 & WIN & 2.53 \\
14 & CUS & 3.75 & 39 & HUM & 2.85 & 64 & PIN & 2.53 & 89 & WON & 3.36 \\
15 & DAX & 4.90 & 40 & JAM & 2.76 & 65 & PIT & 3.27 & 90 & WUD & 6.67 \\
16 & DIH & 6.78 & 41 & JUX & 6.75 & 66 & PUY & 8.14 & 91 & WUJ & 8.34 \\
17 & DIM & 2.98 & 42 & KIL & 3.72 & 67 & QAL & 7.12 & 92 & YEC & 6.96 \\
18 & DOHI & 2.49 & 43 & KUJ & 8.39 & 68 & RAN & 2.51 & 93 & YEG & 6.48 \\
19 & FED & 3.10 & 44 & LAB & 2.84 & 69 & RED & 2.68 & 94 & YOR & 5.68 \\
20 & FET & 5.18 & 45 & LAW & 3.11 & 70 & REP & 4.18 & 95 & ZAB & 5.00 \\
21 & FIG & 3.70 & 46 & LEB & 4.21 & 71 & REX & 3.80 & 96 & ZIN & 5.21 \\
22 & FIX & 3.55 & 47 & LIP & 2.75 & 72 & ROB & 3.26 & 97 & ZIY & 8.00 \\
23 & FOG & 3.76 & 48 & LUX & 4.32 & 73 & RUM & 2.76 & 98 & ZOG & 5.86 \\
24 & FOR & 3.24 & 49 & MAN & 2.34 & 74 & RUK & 6.43 & 99 & ZOJ & 8.38 \\
25 & FOX & 3.44 & 50 & MEN & 2.58 & 75 & SET & 2.38 & 100 & ZUM & 4.88 \\
\hline
\end{tabular}

vided above it is clear that the Underwood-Schulz method for quantifying the pronounceability of CVC trigrams yields high within-population reliability co- efficients as well as a high between-population correlation coefficient. The Montana norms for the p scale appear to regress linearly on the Georgia norms, with $98.6 \%$ of the variance accounted for by Eq. 2 . There is a slight tendency for the northwesterm Ss to give higher ratings than southeastern Ss to the CVCs in the "Easy" category, and to give comparatively lower ratings to CVCs in the "Average" and "Hard" categories. In conclusion, because of the larger sample size and the two diverse populations that have been combined, the $100 \overline{\mathrm{p}}$ values shown in Table 1 are recommended for maximum reliability in future research on pronounceability.

\section{References}

Noble, C. E. Measurements of association value (a), rated associations $\left(a^{\prime}\right)$, and scaled meaningfulness $\left(m^{*}\right)$ for the $2100 \mathrm{CVC}$ combinations of the English alphabet. Psychol. Rep., 1961, 8, 487-521.

Noble, C. E. Meaningfulness and familiarity. In C. N. Cofer \& B. S. Musgrave (Eds.), Verbal behavior and learning: problems and processes. New York: McGraw-Hill, 1933. Pp. 76-119.

Underwood, B. J., \& Schulz, R.W. Meaningfulness and verbal learning. Chicago: Lippincott, 1960.

\section{Note}

1. This report was prepared with support from the Office of Naval Research under Contract Nonr-3677 (02) and from the Air Force Office of Scientific Research under AFOSR Grant 1099-66. Reproduction in whole or in part is permitted for any purpose of the United States Government. Assisting in data analysis were Joan E. Eldodt, Sam J. Hagan, Helen R. Jones, and Charles A. Warren. 